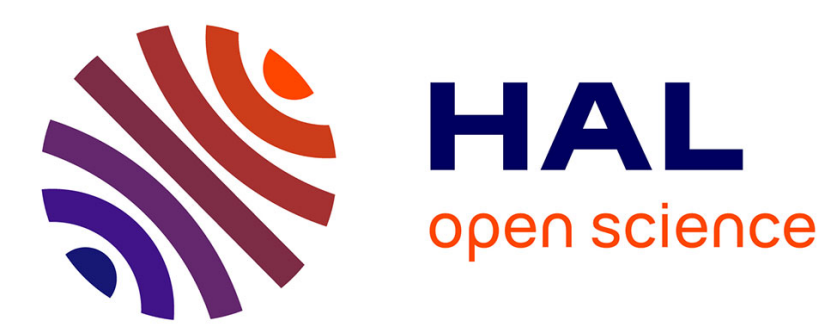

\title{
An alternative way to orient the parent phase in the cubic/orthorhombic martensitic transformation of titanium shape memory alloys
}

Emmanuel Bertrand, Philippe Castany, Thierry Gloriant

\section{- To cite this version:}

Emmanuel Bertrand, Philippe Castany, Thierry Gloriant. An alternative way to orient the parent phase in the cubic/orthorhombic martensitic transformation of titanium shape memory alloys. Scripta Materialia, 2014, 83, pp.41-44. 10.1016/j.scriptamat.2014.04.012 . hal-00995659

\section{HAL Id: hal-00995659 \\ https://hal.science/hal-00995659}

Submitted on 23 May 2014

HAL is a multi-disciplinary open access archive for the deposit and dissemination of scientific research documents, whether they are published or not. The documents may come from teaching and research institutions in France or abroad, or from public or private research centers.
L'archive ouverte pluridisciplinaire HAL, est destinée au dépôt et à la diffusion de documents scientifiques de niveau recherche, publiés ou non, émanant des établissements d'enseignement et de recherche français ou étrangers, des laboratoires publics ou privés. 
An alternative way to orient the parent phase in the cubic/orthorhombic martensitic transformation of titanium shape memory alloys

\author{
Emmanuel Bertrand ${ }^{1, *}$, Philippe Castany ${ }^{2}$, Thierry Gloriant ${ }^{2}$ \\ ${ }^{1}$ Institut des Matériaux Jean Rouxel (IMN), Université de Nantes, CNRS, Rue Christian \\ Pauc, BP 50609, 44306 Nantes Cedex 3, France \\ ${ }^{2}$ INSA Rennes, Institut des Sciences Chimiques de Rennes (ISCR CNRS 6226), 20 \\ avenue des Buttes de Coësmes, F-35708 Rennes Cedex 7, France \\ *Corresponding author: emmanuel.bertrand@univ-nantes.fr \\ Tel.: +33240683128, Fax: +33240683199
}

\begin{abstract}
Titanium-based shape memory alloys undergo a cubic to orthorhombic martensitic transformation ( $\beta$ to $\alpha$ " martensite). A new easy way operating as a reconstruction of the parent microstructure is used from electron backscattered diffraction. It is shown that the electron backscattered patterns of the martensitic microstructure can be directly indexed as the parent phase in order to obtain the correct orientation of the high temperature microstructure. This method is however specific to the cubic/orthorhombic martensitic transformation in titanium shape memory alloys.
\end{abstract}

Keywords: EBSD; Phase reconstruction; Titanium; Shape memory alloys

Electron BackScattered Diffraction (EBSD) measurements are commonly used in order to determine the Orientation Relationships (OR) between the parent phase and the product phase that exists in displacive transformations and enables to determine the crystallographic orientation of the high temperature phase before transformation. This technique which is named phase reconstruction was already used for the $\alpha / \beta$ transformation of titanium and zirconium alloys [1-4] or for the martensitic transformation in steels [5-7].

In titanium alloys, the OR between the stable low temperature $\alpha$ phase and high temperature $\beta$ phase is known as Burgers relationship. However, the application of the OR on the $\alpha$ phase (hexagonal) is not sufficient to determine the orientation of the $\beta$ (body-centered-cubic) parent phase because there are 6 equivalent ways to apply the OR on the $\alpha$ phase leading to 6 possible different $\beta$ orientations $[1,3]$. It is thus not possible to determine exactly the 
orientation of the former $\beta$ phase with this technique and the real orientation has to be determined at high temperature, on residual $\beta$-phase existing at room temperature or by other advanced techniques [4]. In Ti-based alloys, it also exists the metastable martensitic orthorhombic $\alpha$ " phase, which can be obtained by quenching from the high temperature $\beta$ phase domain. Indeed, in the case of metastable $\beta$ titanium alloys, a sufficient amount of $\beta$ stabilizing elements (such as $\mathrm{Ta}, \mathrm{Nb}, \mathrm{Mo}, \mathrm{V} \ldots$ ) allows the reversible martensitic $\beta / \alpha$ ' transformation [8-11]. A major application of titanium alloys showing such a displacive transformation is the production of shape-memory or superelastic nickel-free biocompatible alloys for medical applications [10,12-14] The martensitic $\alpha$ " phase has a C-centered orthorhombic structure and the $\beta / \alpha$ " OR is described in literature as a Burgers type except that the shear and atomic shuffle from the $\beta$ to the hexagonal $\alpha$ phase do not go to completion [15]. The Burgers OR becomes thus for this $\beta / \alpha^{\prime \prime}$ transformation $[9,16]:(-110)_{\beta} / /(001)_{\alpha}{ }^{\prime}$, and $[111]_{\beta} / /[110]_{\alpha}$. An illustration of the correspondence between structures of the $\beta$ phase and the $\alpha$ " martensite is given in supplementary material. By application of the OR, each $\beta$ grain is decomposed during the quench into several possible $\alpha$ " variants by application of 6 possible lattice correspondences, leading to a $\alpha$ " selfaccommodating room temperature microstructure [17] and a shape memory effect $[8,18]$.

The shape memory effect comes from the fact that there is one unique path to do the inverse transformation upon heating. From the crystallographic point of view, this means that each of the six $\alpha$ " variant can only transform into a same and unique parent crystal. Hence, the crystallographic reconstruction of the parent phase in an $\alpha$ " microstructure is expected to be simpler than for other martensitic transformations, for which several paths to do the inverse transformations are possible $[1,3]$. A classical way to reconstruct the parent phase would be to apply the OR on each lath of $\alpha$ " martensite. However, the microstructure in such shape memory alloys in usually very fine with nano-sized laths $[15,17]$ leading to difficulties (or impossibility in some cases) to index individual lath by EBSD and thus reconstruct the orientation of the parent phase from martensite indexation. The objective of this paper is to show, in the specific case of the cubic to orthorhombic martensitic transformation, the possibility to directly determine the crystallographic orientation of the high temperature parent phase from the room temperature martensitic microstructure by indexing Electron BackScatter Patterns (EBSPs) without any further data processing and without indexation of the martensite. 
The composition of the alloy for this study is Ti-25Ta-20Nb (mass\%). It underwent an annealing at $850^{\circ} \mathrm{C}$ for $0.5 \mathrm{~h}$, followed by water quenching in order to obtain the $\alpha$ ' -phase microstructure. Preliminary experiments showed that this alloy exhibits a shape memory effect with austenite start and austenite finish temperatures of $\mathrm{A}_{\mathrm{s}}=205^{\circ} \mathrm{C}$ and $\mathrm{A}_{\mathrm{f}}=232^{\circ} \mathrm{C}$, respectively. The phases repartition is determined by X-ray diffraction (XRD) using a Bruker D8 Advance diffractometer with LynxEye detector and $\mathrm{Cu} \mathrm{K} \alpha$ radiation. EBSD studies are carried out in a Merlin scanning electron microscope (SEM) from Carl Zeiss equipped with a Nordlys 2 camera. An accelerating voltage of $20 \mathrm{kV}$ and a probe current of $3000 \mathrm{pA}$ are used. The samples were prepared by mechanical polishing to a "mirror finished" state. Chemical etching with a solution of $5 \% \mathrm{HF}, 5 \% \mathrm{HNO}_{3}$ and $90 \% \mathrm{H}_{2} \mathrm{O}$ (vol. \%) was used to remove the residual deformation layer induced by polishing.

Fig. 1 shows EBSD maps of the water quenched Ti-25Ta-20Nb sample and the X-rays diffractogram. The diffractogram (Fig. 1d) shows that the sample is only composed of $\alpha$ " martensitic phase which lattice parameters, known to be dependent on the chemical composition [9], are measured as: $\mathrm{a}=0.3174 \mathrm{~nm}, \mathrm{~b}=0,4826 \mathrm{~nm}$ and $\mathrm{c}=0,4638 \mathrm{~nm}$. The Band Contrast (BC) map (Fig. 1a) is used to reveal the microstructure. Hence, grain boundaries and martensite/martensite interfaces have a lower crystallinity than the rest of the microstructure and appear darker. One can observe large domains delimited by dark lines corresponding to the lowest $\mathrm{BC}$, which seem to correspond to grain boundaries of former $\beta$ grains present at high temperature: these dark lines are thus a signature of the high temperature $\beta$ microstructure. These ex- $\beta$ grains will be called grains further in this paper. In these grains, a microstructure made of laths and needles is also visible. This thinner microstructure corresponds to a mix of the different possible variants of $\alpha$ ". The BC map confirms the effect of the thermal treatment: the $\beta$ microstructure at high temperature is decomposed into $\alpha$ " martensite when the alloy is quenched. Fig. 1b shows the orientations represented by Euler angles (see color online) when the EBSPs are indexed using the $\alpha$ " phase. The largest laths are unambiguously oriented while the orientation of some domains with a thinner microstructure is more imprecise. Indeed, the indexation rate is close to $60 \%$ which is mainly due to a nanometric sized $\alpha$ " microstructure in some domains [15,17]. However, five different $\alpha$ " orientations are unambiguously detected in the largest laths in the grain at the center of the figure. As it will be shown further, all these five $\alpha$ " variants are formed from the same $\beta$ grain at high temperature (delimited by the dark lines on Fig. 1a).

Usually, reconstruction of the parent phase orientation should be made by applying the Burgers OR on the orientation of each $\alpha^{\prime \prime}$ variant found previously, needing additional 
calculations. Another possible way to determine the orientation of the parent $\beta$ phase would be to index the residual $\beta$ phase by EBSD, but it is impossible in the present case since there is no $\beta$ phase in the microstructure (see XRD result in Fig. 1d). In order to determine easily and directly the orientation of the $\beta$ parent phase, the idea is now to force the indexation of the same EBSPs acquired previously with the $\beta$ phase, even if, of course, there is no $\beta$ phase in the microstructure. If the choice between the $\alpha^{\prime \prime}$ and $\beta$ phases was let possible, the EBSD software would select automatically the $\alpha$ " phase to index the EBSPs due to a better matching than with the $\beta$ phase. That is why only the $\beta$ phase is proposed in the EBSD software as possible phase in order to force the indexation with the parent phase. However, all EBSPs cannot be indexed with the $\beta$ phase, but relatively few can be indexed because of the similarity of both phases. As a consequence, the indexation rate drops to $25 \%$. Even if this value is dramatically low, there is no area wherein no pixel is indexed: indexed pixels are thus uniformly distributed in each ex- $\beta$ grain (even when the $\alpha$ " microstructure is very thin) making a noise reduction by neighbor extrapolation possible (Fig. 1c). Moreover, the asobtained orientations of the $\beta$ phase are now delimiting grain boundaries that correspond to the expected ex- $\beta$ grain highlighted in the BC map (Fig. 1a). Each ex- $\beta$ grain is thus actually indexed as a unique $\beta$ orientation from this method, i.e. each $\alpha^{\prime \prime}$ variant in a given ex- $\beta$ grain is indexed as a same and unique $\beta$ orientation, as theoretically expected. It will also be shown further that the obtained orientation of the $\beta$ phase is accurate in spite of the very low indexation rate. In turn, although the sample is only composed of $\alpha$ " phase (Fig. 1d), directly indexing the EBSPs with the $\beta$ phase operates as a crystallographic reconstruction of the parent phase.

It is now necessary to verify if the orientation of the $\beta$ phase found by this "direct reconstruction" corresponds to its real orientation. In order to verify this orientation, the OR with the $\alpha$ " martensite is first tested and, finally, a thermal treatment is performed to allow a direct indexation of the real $\beta$ phase by EBSD.

The pole figures of the $\beta$ orientation and the five $\alpha$ " orientations obtained from EBSPs indexation are given in Fig. 2. It can be clearly seen that the $(001)_{\alpha}$ " pole of each $\alpha^{\text {" variant }}$ corresponds to a $\{110\}_{\beta}$ pole of the $\beta$ parent phase and each $[110]_{\alpha}$ " direction corresponds to a $[111]_{\beta}$ direction, which is in accordance with the OR between these two phases. The maximum misfit between poles of the two phases is $2^{\circ}$ but is mainly measured to be lower than $1^{\circ}$ (Fig. 2). Moreover, each different $\alpha$ " variant gives a same and unique orientation of the $\beta$ phase that is consistent with the expected microstructure of a shape memory alloy. The 
orientation of the $\beta$ phase determined by direct reconstruction is thus in accordance with the OR applied with the five $\alpha$ " orientations that are really present in the microstructure: the direct indexation of the martensitic phase by the parent $\beta$ phase respects the OR.

Once the crystallographic reconstruction is achieved, one technical difficulty is to evaluate the error made on the orientation of the reconstructed crystal. This is generally done by orienting the residual high temperature phase ( $\beta$ phase in titanium alloys or austenite in steels) [4]. With the alloy family that is studied in this paper, no residual $\beta$ phase is present in the microstructure, but it is possible to obtain the high temperature parent phase at room temperature after a short annealing above $\mathrm{A}_{\mathrm{f}}$ temperature followed by air cooling. The same sample investigated previously (Fig. 1) is thus annealed at $300^{\circ} \mathrm{C}$ for 1 minute and then air cooled to obtain the real $\beta$ microstructure. A short annealing duration is required to prevent significant formation of $\omega$ phase which is favored in this temperature domain. As previously, the sample is then prepared once again for EBSD characterization by mechanical polishing and chemical etching. Fig. 3 shows an EBSD mapping of the same area as in Fig. 1 and the associated X-ray diffractogram after annealing. The grain morphology is quite different to the Fig. 1 due to the thin metallic layer that is removed during the new polishing step. It is clear that the lath morphology inherited from the martensitic transformation is no more present, and the indexation rate is now excellent (over 99\%) when EBSPs are indexed with the $\beta$ phase. The diffractogram also confirms that the sample is mostly composed of $\beta$ phase (Fig $3 b$ ). A few amount of $\omega$ phase is also detected. But, as $\omega$ phase is known to be nanometric sized and fully coherent with the $\beta$ phase [16,19], its presence has not effect on the EBSPs indexation. The parent phase microstructure obtained at room temperature after annealing is thus suitable to be compared with the orientation that was obtained by direct crystallographic reconstruction from the martensitic microstructure. An accurate measurement of the misorientation between the ex- $\beta$ grain in the center of Fig. 1 and the same $\beta$ grain on Fig. 3 is $4.4^{\circ}$. This operation is done on each grain of the map and gives an average value of $5.2^{\circ}$. These relatively high values of misorientation are mainly due to the experimental conditions (annealing, sample repreparation and sample repositioning in the SEM between the two mappings). In order to prove that, the classical phase reconstruction is used in order to reconstruct the ex- $\beta$ grain at the center of the figure, i.e. the OR is applied on each variant of martensite which is detected in this grain. The difference between this classical method and the one which is proposed in this paper is of $1.1^{\circ}$ in average, proving that the rest of the error is due to the experimental conditions. It confirms that the $\beta$ orientation that is determined on 
Fig. 2c from the martensitic microstructure corresponds to the actual orientation of the parent phase. The "direct reconstruction" from the martensitic microstructure gives thus the real orientation of the former high temperature phase with a rather good precision in spite of a very low indexation rate.

Obtaining the orientation of the parent phase by indexing EBSPs of martensite as it was the parent phase can seem very peculiar. This orientation matching can be explained by the similarity of the EBSPs of the two phases. As an example, Fig. 4 shows a simulated EBSP based on the Euler angles obtained from the $\beta$ indexation of Fig. $1 \mathrm{c}$ and a simulated EBSP obtained with one of the five $\alpha$ " orientations determined on the same domain (Fig. 1b). One can observe that the main Kikuchi band intersections on Fig. 4a and Fig. $4 \mathrm{~b}$ match very closely. Moreover, the (101) $)_{\beta}$ pole matches exactly to the $(001)_{\alpha} "$ pole, confirming that the OR is directly applicable for the indexation of the EBSPs of $\alpha^{\prime \prime}$ phase by the $\beta$ phase. This similarity of EBSPs is due to the similarity of both structures wherein positions of atoms are very near: a small displacement of some atoms of the $\beta$ phase leads to the orthorhombic structure of the martensite.

As a summary, we demonstrate that the orientation of the high temperature parent $\beta$ phase in titanium shape memory alloys can be easily obtained from EBSD experiments by directly indexing the $\alpha$ " martensitic microstructure with the parent phase. The quality of indexation decreases but is sufficient to obtain the real orientation of the parent phase, even if this phase is not present in the microstructure. This new method does not need any further data processing after EBSD experiments and is easier than those commonly used. But this method works when martensite can only transform into a same and unique parent crystal with simple martensitic transformations such as body-centered cubic to orthorhombic. It would not work with more complex transformations such as bcc to hcp or fcc to bcc. As it does not need indexation of the martensite, it can also be applied when the martensitic microstructure is too thin to be indexed unambiguously by EBSD to allow classical reconstruction.

\section{References}

[1] Humbert M, Wagner F, Moustahfid H, Esling C. J Appl Crystallogr 1995;28:571.

[2] Gey N, Humbert M. J Mater Sci 2003;8:1289.

[3] Glavicic MG, Kobryn PA, Bieler TR, Semiatin SL. Mater Sci Eng A 2003;351:258. 
[4] Germain L, Gey N, Humbert M. Ultramicroscopy 2007;107:1129.

[5] Cayron C, Artaud B, Briottet L. Mater Charact 2006;57:386.

[6] Miyamoto G, Iwata N, Takayama N, Furuhara T. Acta Mater 2010;58:6393.

[7] Germain L, Gey N, Mercier R, Blaineau P, Humbert M. Acta Mater 2012;60:4551.

[8] Buenconsejo PJS, Kim HY, Hosoda H, Miyazaki S. Acta Mater 2009;57:1068.

[9] Kim HY, Ikehara Y, Kim JI, Hosoda H, Miyazaki S. Acta Mater 2006;54:2419.

[10] Bertrand E, Gloriant T, Gordin DM, Vasilescu E, Drob P, Vasilescu C, Drob SI. J Mech Behav Biomed Mater 2010;3:559.

[11] Bertrand E, Castany P, Gloriant T. Acta Mater 2013;61:511.

[12] Niinomi M. J Mech Behav Biomed Mater 2008;1:30.

[13] Laheurte P, Prima F, Eberhardt A, Gloriant T, Wary M, Patoor E. J Mech Behav Biomed Mater 2010;3:565.

[14] Ramarolahy A, Castany P, Prima F, Laheurte P, Péron I, Gloriant T. J Mech Behav Biomed Mater 2012;9:83.

[15] Banerjee D, Muraleedharan K, Strudel JL. Philos Mag A 1998;77:299.

[16] Morniroli JP, Gantois M. Mémoires Sci la Rev Métallurgie 1973;70:831.

[17] Chai YW, Kim HY, Hosoda H, Miyazaki S. Acta Mater 2009;57:4054.

[18] Ping D, Mitarai Y, Yin F. Scr Mater 2005;52:1287.

[19] Prima F, Vermaut P, Texier G, Ansel D, Gloriant T. Scr Mater 2006;54:645. 

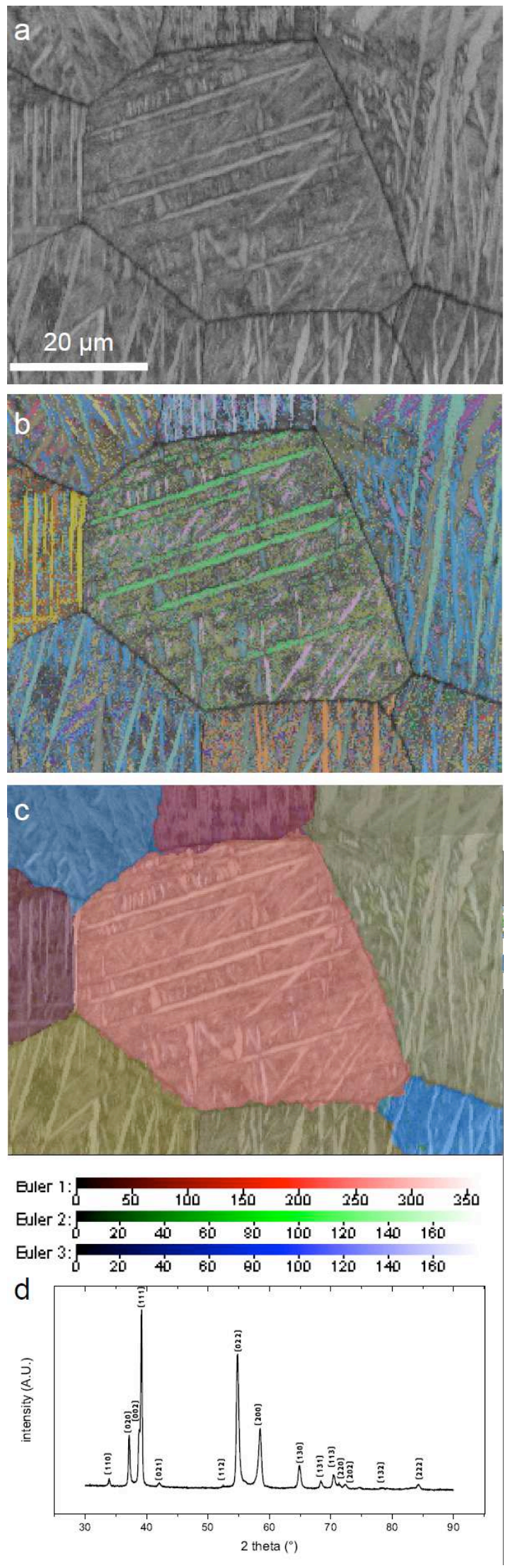

Fig. 1. EBSD maps of Ti-25Ta-20Nb alloy: band contrast (BC) only (a); BC superimposed to Euler angles obtained from indexation with the $\alpha$ " phase (b); BC superimposed to Euler angles obtained from indexation with the $\beta$ phase (c); X-rays diffractogram (d). 


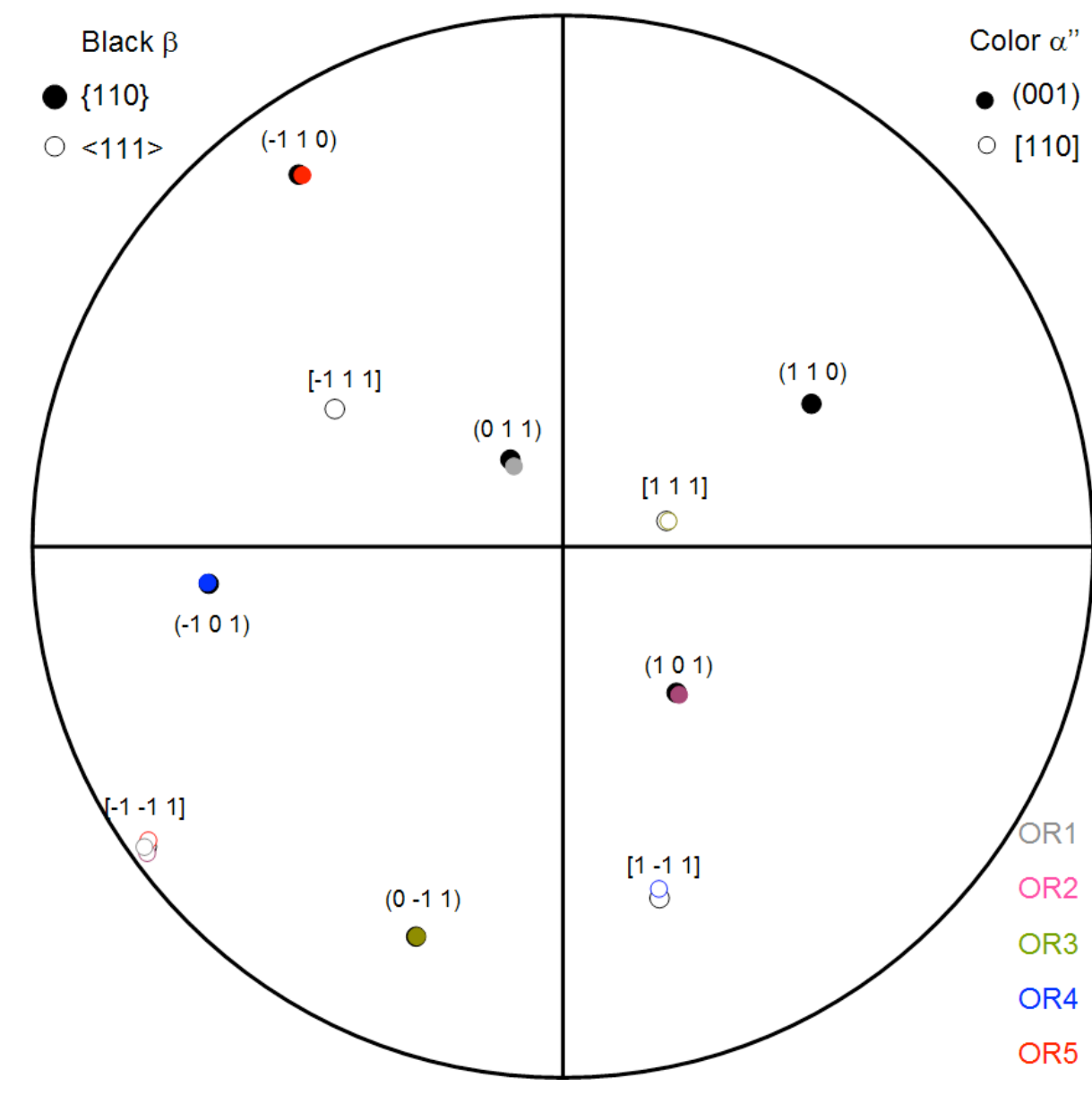

Fig. 2. Poles figure of the ex- $\beta$ grain in the center of the Fig. 1. The $\{110\}_{\beta}$ and $\langle 111\rangle_{\beta}$ obtained from EBSD indexation are superimposed to the (001) $)^{\prime}$ and [110] " of the five orientations of $\alpha^{\prime \prime}$ detected by EBSD. 


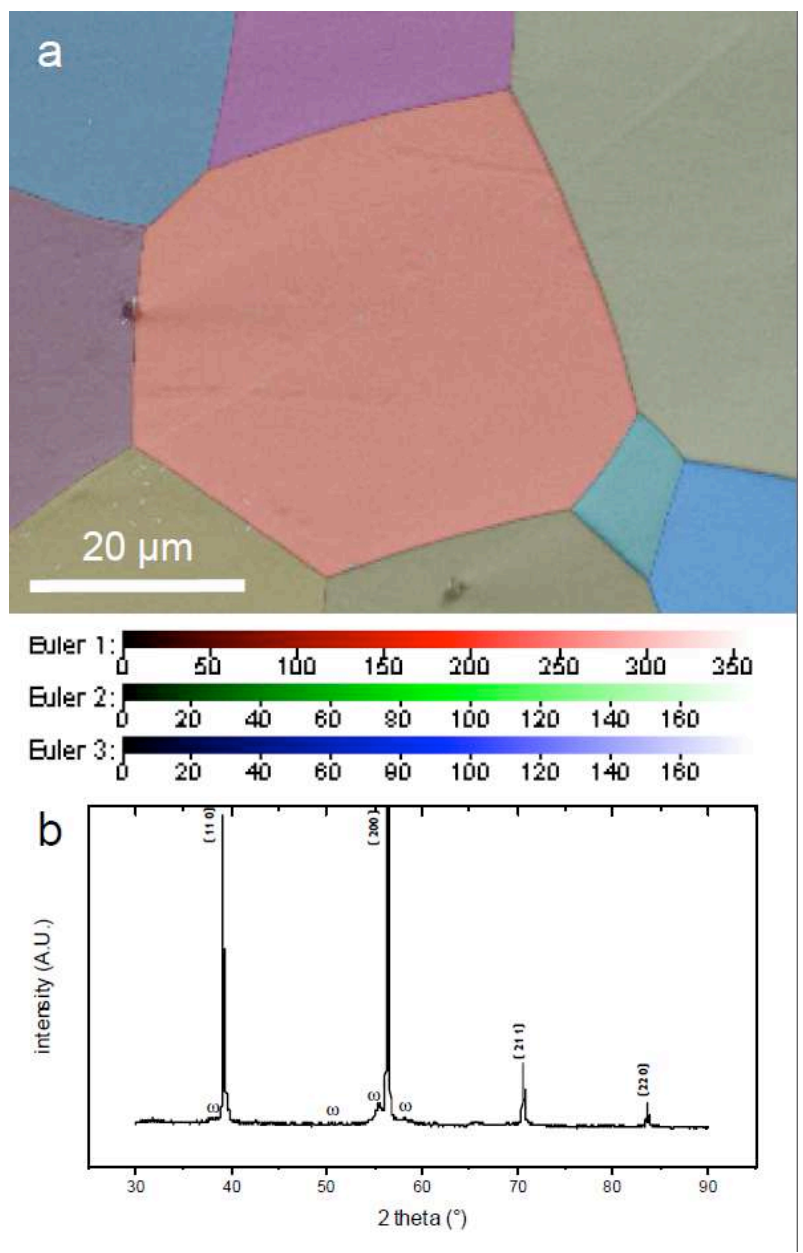

Fig. 3. EBSD mapping of the same area as in Fig. 1 after annealing: band contrast and Euler angles from $\beta$ indexation (a) and X-rays diffractogram (b). 

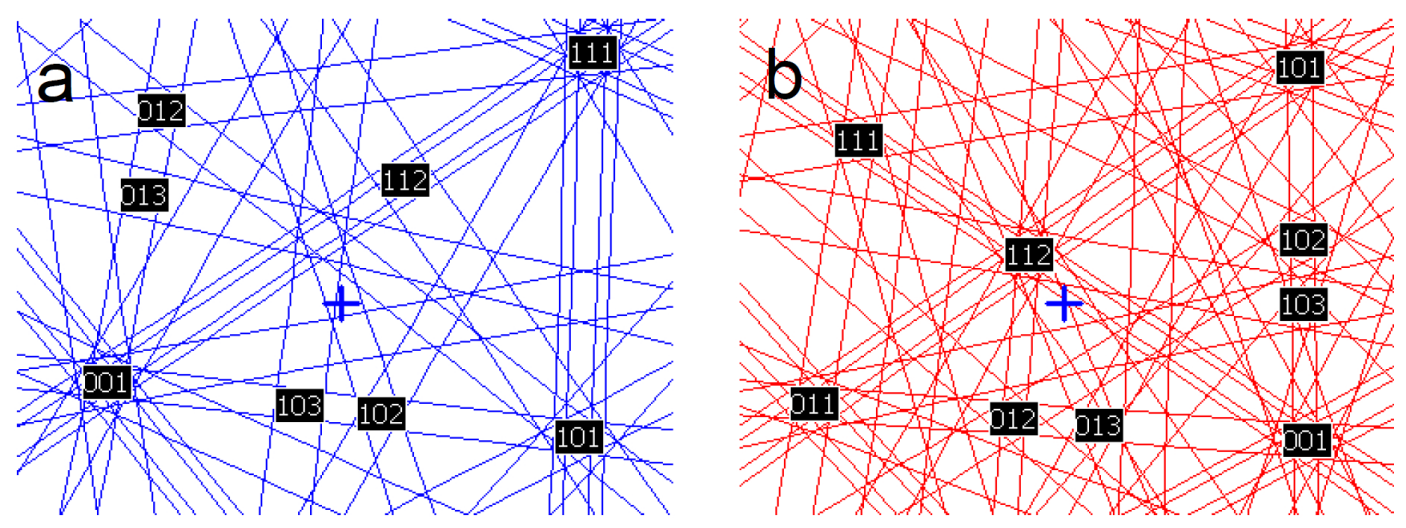

Fig. 4. Simulated EBSP of the $\beta$ phase orientation of the ex- $\beta$ grain in the center of Fig. $1 c$ (a) and one of the $\alpha$ ' orientation determined on Fig. $1 b$ in the same ex- $\beta$ grain (b).

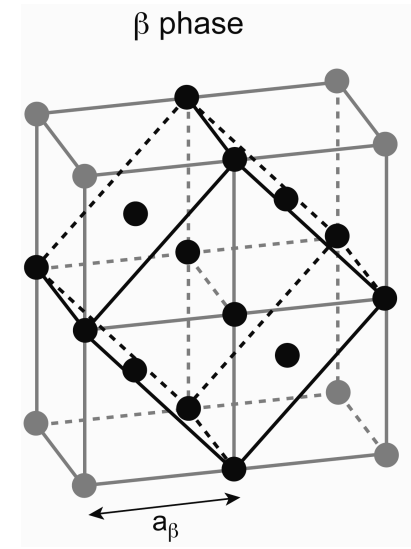

$\alpha$ " martensitic phase

Supplementary Information. Correspondence between structures of the body-centered cubic $\beta$ phase and the C-centered orthorhombic $\alpha$ " phase. 